\title{
HUBUNGAN PERILAKU PEKERJA DENGAN PENGGUNAAN ALAT PELINDUNG DIRI (APD) DI PABRIK PENGGILINGAN PADI KABUPATEN SIDRAP Erlani ${ }^{1}$ dan Anugrah. $\mathbf{S}^{2}$ \\ ${ }^{1.2}$ Poltekkes Kemenkes Makassar \\ anugerahi1996@gmail.com
}

\begin{abstract}
The rapid development of industry in Indonesia, both in the formal and informal sectors, will create new jobs and absorb a new workforce. In 2001 the workforce numbered 101 million people, most (70-80\%) in the informal sector. PPE usage behavior is influenced or determined by factors both from within and from outside the subject. Also, several factors allow a worker to behave in using PPE when doing work. The purpose of this study was to determine the relationship of worker behavior with the use of personal protective equipment (PPE) in the Sidrap District rice mills. The research method used is an analytic survey with a crosssectional approach, where data concerning independent and bound variables will be collected at the same time and directly. The results showed that of the 120 respondents, namely 54 respondents (54.0\%) who were categorized highly knowledgeable, and 33 respondents (36.9\%) who used PPE, while those with low knowledge were 66 respondents (66.0\%) and 17 respondents (20.09\%) who do not use PPE. 32 (26.7\%) had a worker attitude category there were 54 (54\%) had a high attitude category and 40 (41.4\%) used PPE, did not use 14 (15.4\%) workers were in a low attitude 66 (66\%) workers In the Sidrap Regency rice mill, 52 respondents (50.1\%) were categorized as having high actions 54 (54\%) respondents and those who did not use 5 (3.8\%) categorized as low actions 66 (66\%). The conclusion of this research shows that there is no relationship between worker behavior and the use of PPE Keyword: behavior, knowledge, attitude, and PPE
\end{abstract}

\section{ABSTRAK}

Perkembangan industri yang pesat di Indonesia, baik di sektor formal maupun informal, akan menimbulkan lapangan kerja baru dan menyerap angkatan kerja baru. Pada tahun 2001 angkatan kerja berjumlah 101 juta orang yang sebagian besar (70$80 \%$ ) berada disektor informal. Perilaku pemakaian APD dipengaruhi atau ditentukan oleh faktor-faktor baik dari dalam diri maupun dari luar subjek. Selain itu ada beberapa faktor yang memungkinkan seorang pekerja berperilaku dalam menggunakan APD pada saat melakukan pekerjaan. Tujuan penelitian ini untuk mengetahui hubungan perilaku pekerja dengan pengunaan alat pelindung diri (APD) di pabrik penggilingan padi kabupaten sidrap. Metode penelitian yang digunakan adalah survei analitik dengan pendekatan cross sectional, dimana data yang menyangkut variabel bebas dan terikat akan dikumpulkan dalam waktu yang bersamaan dan secara langsung. Hasil penelitian diperoleh hasil bahwa dari 120 responden yang yaitu 54 responden (54,0\%) yang dikategorikan berpengetahuan tinggi, dan 33 responden (36.9\%) yang mengunakaan APD, sedangkan yang berpengetahuan rendah 66 responden $(66,0 \%)$ dan 17 responden (20.09\%) yang tidak mengunakan APD. terdapat $32(26,7 \%)$ mempunyai kategori sikap pekerja terdapat 54 (54\%) mempunyai kategori sikap tinggi dan 40 (41.4\%) yang mengunakan APD, tidak menggunakan 14 (15.4\%) pekerja berada dalam sikap rendah 66 (66\%) pekerja di pabrik penggilingan padi kabupaten sidrap, untuk tindakan 52 responden $(50.1 \%)$ di kategorikan memiliki tindakan yang tinggi $54(54 \%)$ responden dan yang tidak menggunakan 5 (3.8\%) di kategorikan tindakan yang rendah 66 (66\%). Kesimpulan dari peneliti ini menunjukkan bahwa tidak terdapat hubungan perilaku pekerja dengan pengunaan APD

Kata Kunci : perilaku, pengetahuan, sikap, dan APD

\section{PENDAHULUAN}

Kondisi industri informal dalam hal keselamatan dan kesehatan kerja (K3) masih sangat kurang memadai dan juga kurang mendapat perhatian dari instansi terkait. Pekerja di industri informal kurang mendapatkan promosi dan pelayanan kesehatan yang memadai, tidak sesuai rancangan tempat kerja, kurang baiknya prosedur atau pengorganisasian kerja, dan kurangnya peralatan pelindung bagi pekerja. Internationa Labor Organitation (ILO) mengungkapkan bahwa setiap tahun terjadi 2,2 juta kematian yang disebabkan karena penyakit atau kecelakaan akibat hubungan tenaga kerjaan. Sekitar 270 juta kasus kecelakaan kerja dimana diperkirakan terjadi 160 juta penyakit akibat hubungan tenaga kerjaan baru setiap tahunnya. (Ahmad, 2006).

Secara umum penyebab kecelakaan dikarenakan oleh faktor manusia (unsafe action) dan faktor lingkungan (unsafe condition).
Berdasarkan hirarki pengendalian risiko bahaya dapat dikendalikan dengan cara eliminasi, subtitusi, pengendalian teknis, pengendalian administratif dan penggunaan (APD). Penggunaan (APD) terhadap tenaga kerja merupakan pilihan terakhir, apabila eliminasi, subtitusi, pengendalian teknis dan pengendalian administratif tidak dapat dilakukan atau dapat dilakukan namun masih terdapat potensi bahaya terhadap pekerja. (Rahayu, 2010).

Perilaku pemakaian APD dipengaruhi atau ditentukan oleh faktor-faktor baik dari dalam diri maupun dari luar subjek. Selain itu ada beberapa faktor yang memungkinkan seorang pekerja berperilaku dalam menggunakan APD pada saat melakukan pekerjaan. Sesuai dengan teori Lawrence Green, terdapat tiga faktor yaitu faktor predisposisi, faktor enabling, reinforcing. Teori ini menjelaskan bahwa faktor-faktor yang mempengaruhi perilaku seseorang antara lain: 
pengetahuan, sikap (predisposisi) kemudian dipegaruhi oleh faktor pendukung (enabling) yaitu ketersediaan atau fasilitas dan sarana prasarana kemudian diperkuat dengan adanya faktor pendorong (reinforcing) yaitu adanya pengawasan dari pihak perusahaan. (Rinawati, 2016)

\section{METODE PENELITIAN}

\section{Jenis Penelitian}

Metode penelitian yang digunakan adalah survei analitik dengan pendekatan cross sectional, dimana data yang menyangkut variabel bebas dan terikat akan dikumpulkan dalam waktu yang bersamaan dan secara langsung.

\section{Penelitian:}

Pabrik penggilingan padi kacamatan watang pulu kabupaten sidrap.

\section{Variabel Penelitian}

Variabel bebas dalam penelitian ini Pengetahuan, Sikap tindakan pekerja di pabrik ,Variabel terikat dalam penelitian ini penggunaan alat pelindung diri (APD), Variabel pengganggu dalam penelitian ini lama masa kerja dan umur dalam hal ini tidak diteliti.

\section{Populasi dan Sampel}

\section{a. Populasi}

Adapun populasi dalam penelitian ini adalah pekerja dibagian produksi dan bagian pengering pekerja yaitu semua pekerja/karyawan yang ada di Pabrik penggilingan padi kabupaten sidrap yang berjumlah kurang lebih 30 pabrik penggilingan padi

b. Sampel

Sampel dalam penelitian ini adalah 120 pekerja/karyawan di Pabrik penggilingan padi kabupaten sidrap yang diambil terdiri dari 3 pabrik yang berbeda dengan teknik pengambilan sampel yang dilakukan dengan cara sampel total (keseluruhan populasi yang berjumlah 120 pekerja/karyawan) dari 3 pabrik tersebut.

\section{Teknik Pengumpulan Data}

\section{a. Data Primer}

Pengambilan secara langsung pada tenaga kerja melalui wawancara dengan menggunakan kuisioner observasi untuk penggunaan alat pelindung diri.

\section{b. Data Sekunder}

Data sekunder adalah data yang ada hubungannnya dengan judul penelitian yang diperoleh dari hasil studi kepustakaan serta literatur-literatur yang ada hubungannya dengan penelitian sebelumnya, internet dan buku-buku mengenai keselamatan dan kesehatan kerja

\section{Analisis Data}

Dalam tahap ini data diolah dan dianalsis dengan teknik-teknik tertentu. Data kualitatif diolah dengan teknik analisis kualitatif, sedangkan data kuantitatif dengan menggunakan teknik analisis kuantitatif. Untuk pengolahan data kuantitatif dapat dilakukan dengan tangan melalui proses komputerisasi. Dalam pengolahan ini mencakup tabulasi data dan perhitungan-perhitungan statistik. Adapun data yang diperoleh dari hasil pengukuran dilapangan diolah dengan menggunakan uji statistik yaitu analisis univariate yang dilakukan untuk variabel tunggal yang di anggap terkait dengan penelitian dan analisis bevariate untuk melihat distribusi beberapa variabel yang dianggap terkait dengan menggunakan uji ChiSquare $(X)$,

Hasil Penelitian

Penelitian ini dilakukan pada bulan Mei hingga bulan Juli tahun 2018 di pabrik panggilingan padi kabupaten Sidrap. Berdasarkan hasil dari kuesioner dan wawancara yang dilakukan pada 120 pekerja di pabrik penggilingan padi kabupaten sidrap di peroleh hasil sebagai berikut :

Tabel 1

Distribusi Responden Berdasarkan Masa Kerja Di Pabrik Penggilingan Padi Kabupaten Sidrap

\begin{tabular}{|c|c|c|c|}
\hline NO & $\begin{array}{c}\text { Masa kerja / } \\
\text { tahun }\end{array}$ & Jumlah & $\%$ \\
\hline 1. & 1 & 34 & 28 \\
\hline 2. & 2 & 37 & 31 \\
\hline 3. & 3 & 29 & 24 \\
\hline 4. & 4 & 20 & 17 \\
\hline \multicolumn{2}{|r|}{ Total } & 120 & 100 \\
\hline
\end{tabular}

Sumber : Data Primer 2018 
Jurnal Sulolipu : Media Komunikasi Sivitas Akademika dan Masyarakat

Vol. 18 No 22018

e-issn : 2622-6960, p-issn : 0854-624X

Tabel 2

Distribusi Responden Berdasarkan Umur Di Pabrik Penggilingan Padi kabupaten sidrap

\begin{tabular}{cccc}
\hline \hline NO & Kriteria umur & Jumlah & $\%$ \\
\hline 1. & $10-20$ & 28 & 23 \\
2. & $21-30$ & 67 & 56 \\
3 & $31-40$ & 25 & 21 \\
\hline & Total & $\mathbf{1 2 0}$ & $\mathbf{1 0 0}$ \\
\hline
\end{tabular}

Sumber : Data Primer 2018

Tabel 3

Distribusi Responden Berdasarkan penggunaan APD Di Pabrik Penggilingan Padi kabupaten sidrap

\begin{tabular}{|c|c|c|c|}
\hline NO & $\begin{array}{c}\text { Tindakan } \\
\text { penngunaan APD }\end{array}$ & Jumlah & $\%$ \\
\hline 1. & Menggunakan & 53 & 44 \\
\hline 2. & $\begin{array}{c}\text { Tidak } \\
\text { menggunakan }\end{array}$ & 67 & 56 \\
\hline \multicolumn{2}{|c|}{ Total } & $\mathbf{1 2 0}$ & $\mathbf{1 0 0}$ \\
\hline
\end{tabular}

Sumber : Data Primer 2018

Tabel 4

Distribusi Resonden Berdasarkan pengetahuan Di pabrik penggilingan pedi kabupaten sidrap

\begin{tabular}{cccc}
\hline NO & Pengetahuan & Jumlah & $\%$ \\
\hline 1. & Tinggi & 82 & 68 \\
2. & Rendah & 38 & 32 \\
\hline & Total & $\mathbf{1 2 0}$ & $\mathbf{1 0 0}$ \\
\hline
\end{tabular}

Tabel 5

Distribusi Resonden Berdasarkan Sikap Di Pabrik Penggilingan Padi Kabupaten Sidrap

\begin{tabular}{cccc}
\hline NO & Sikap & Jumlah & $\%$ \\
\hline 1. & Tinggi & 54 & 45 \\
2. & Rendah & 66 & 55 \\
\hline & Total & $\mathbf{1 2 0}$ & $\mathbf{1 0 0}$ \\
\hline
\end{tabular}

Sumber : Data Primer 2018
Tabel 5.6

Distribusi Resonden Berdasarkan Tindakan dalam Di Pabrik Penggilingan Padi Kabupaten Sidrap

\begin{tabular}{cccc}
\hline NO & Tindakan & Jumlah & $\%$ \\
\hline 1. & Tinggi & 54 & 45 \\
2. & Rendah & 66 & 55 \\
\hline & Total & $\mathbf{1 2 0}$ & $\mathbf{1 0 0}$ \\
\hline
\end{tabular}

Sumber : Data Primer 2018

Tabel 7

Hubungan Pengetahuan Dengan Penggunaan APD

\begin{tabular}{|c|c|c|c|c|c|c|c|c|}
\hline \multirow{3}{*}{ Pengetahuan } & \multicolumn{4}{|c|}{ Penggunaan APD } & \multirow{3}{*}{ Total } & \multirow{3}{*}{$\%$} & \multirow{3}{*}{$\bar{\alpha}$} & \multirow{3}{*}{$P$} \\
\hline & \multicolumn{2}{|l|}{$\mathrm{Ya}$} & \multicolumn{2}{|c|}{ Tidak } & & & & \\
\hline & $z^{-}$ & $\%$ & $\Sigma$ & $\%$ & & & & \\
\hline Tinggi & 33 & 36.9 & 49 & 45,1 & 82 & 100 & & \\
\hline Rendah & 21 & 17.1 & 17 & 20.09 & 38 & 100 & 0,05 & 0,12 \\
\hline Total & 54 & 54.0 & 66 & 66.0 & 120 & 100 & & \\
\hline
\end{tabular}

Tabel 8

Hubungan Penggunaan APD Dengan Sikap Pekerja

\begin{tabular}{|c|c|c|c|c|c|c|c|c|}
\hline \multirow{3}{*}{ Sikap } & \multicolumn{6}{|c|}{ Penggunaan APD } & \multirow{3}{*}{$\alpha$} & \multirow{3}{*}{$P$} \\
\hline & \multicolumn{2}{|l|}{$\mathrm{Ya}$} & \multicolumn{2}{|l|}{ Tidak } & \multirow[t]{2}{*}{ Total } & \multirow[t]{2}{*}{$\%$} & & \\
\hline & 2 & $\%$ & $\Sigma$ & $\%$ & & & & \\
\hline Tinggi & 40 & 41.4 & 52 & 50.6 & 54 & 100 & & \\
\hline Rendah & 14 & 12.6 & 14 & 15.4 & 66 & 100 & 0,05 & 0,54 \\
\hline Total & 54 & 54 & 66 & 66 & 120 & 100 & & \\
\hline
\end{tabular}

Tabel 9

Hubungan Penggunaan APD Dengan Tindakan

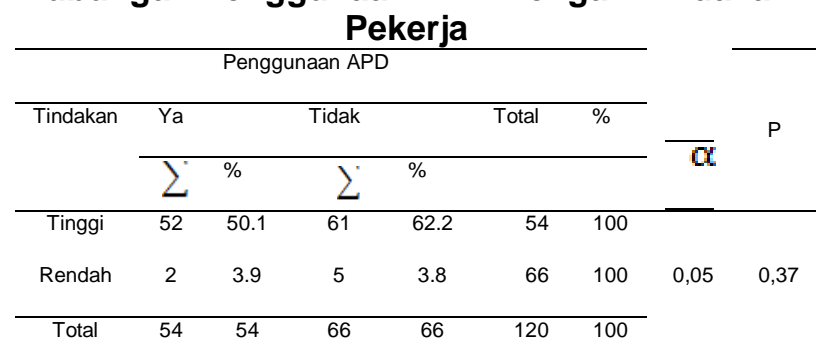


Jurnal Sulolipu : Media Komunikasi Sivitas Akademika dan Masyarakat

Vol. 18 No 22018

e-issn : 2622-6960, p-issn : 0854-624X

\section{Pembahasan}

Pengetahuan adalah merupakan hasil dari tahu dan ini terjadi setelah orang melakukan penginderaan terhadap suatu objek tertentu (Mandangi, 2013). Berdasarkan hasil uji chi square (tabel 5.7) di peroleh $p$ value $0,124 \quad(0,05)$ pengetahuan pekerja tidak mempunyai hubungan terhadap pengunaan APD hal ini disebabkan karena sebagian besar pekerja atau mengtahui tentang alat pelindun diri itu sendiri tapi kebanyakan mereka tidak mengunakannya karena alasan kurang nyaman, menyusahkan, dan terasa kaku pada saat bekerja. Adapun variabel pengganggu seperti umur, jumlah responden pada penelitian ini 120 dengan jenis kelamin laki-laki dengan kelompok umur yang berbeda, umur responden pekerja di pabrik penggilingan padi paling banyak berumur 21-30 tahun (56\%) dan yang paling sedikit pekerjanya berumur 31-40 tahun (21\%). Penelitian ini sejalan dengan penelitian (Dian Fitri Wijayanti 2016) yang menunjukkan bahwa analisis dilakukan dengan uji Chi Square dengan hasil p sebesar 0,109 ( $p>0,05)$ yang menunjukkan bahwa secara statistik tidak terdapat hubungan yang bermakna antara penggunaan APD dengan kejadian keluhan gangguan kulit

Sikap adalah kecenderungan untuk bertindak (praktik). Sikap berjumlah tentu terwujud dalam tindakan, karena untuk terwujudnya tindakan perlu faktor lain adanya fasilitas maupun sarana dan perasaran (Sari, 2010). Berdasarkan hasil uji chi square (tabel 5.8) di peroleh $p$ value $0,544(0,05)$ sikap pekerja/responden tidak mempunyai hubungan terhadap pengunaan APD.

Dari hasil tersebut dapat diketahui bahwa pekerja yang memiliki sikap yang tinggi lebih banyak yang tidak mengunakan APD dibandingkan pekerja pekerja yang memiliki sikap rendah hal ini sebabkan karena beberapa faktor sepeti faktor lingkungan dan kebiasaan pekerja yang berkaitan dengan faktor lingkungan yaitu mereka mengeluh pada saat mengunakan APD di cuaca yang panas itu membuat dalam melakukan pekerjaan mereka tidak nyaman Adapun pariabel pengganggu seperti lama masa kerja dimana bahwa lama masa kerja paling lama masa kerjanya 4 tahun dengan jumlah pekerja 20 orang (17\%), sedangkang paling banyak pekerjanya 37 orang $(31 \%)$ dengan masa kerja 2 tahun. Sikap bukan salah satu faktor yang dominan terhadap pengaruh perilaku penggunaan APD. Sikap dipengaruhi oleh pengetahuan, pikiran dan emosi yang berperan dalam berperilaku menggunakan APD. Ada beberapa tingkatan sikap, dalam penelitian ini, pekerja di pabrik penggilingan padi kabupaten sidrap yaitu menerima atau setuju tetapi belum sampai dalam tahap praktik atau tindakan.

Tindakan adalah uatu sikap yang belum otomatis dalam suatu tindakan, untuk mewujudkan sikap menjadi suatu perbuatan yang nyata, faktor pendukung lain. Tindakan merupakan aturan yang mengadakan adanya hubungan erat antara sikap dan tindakan yang didukung oleh sikap yang mengatakan bahwa sikap merupakan pandangan atau perasaan yang disertai kecenderungan untuk bertindak (Purwanto, 1999).

Berdasarkan hasil uji chi square (tabel 5.9) di peroleh $p$ value $0,368 \quad(0,05)$ tindakan pekerja/responden tidak mempunyai hubungan terhadap pengunaan APD.

Dari hasil tersebut dapat dikaitkan juga dengan pengetahuan dengan sikap responden karena diketahui bahwa pengetahuan responden/pekerja di pabrik penggilingan padi yang berpengetahuan tinggi $82(68 \%)$ responden dan 38 (32\%) responden yang memiliki pengetahuan rendah. Sedangkan diketahui bahwa sikap responden di pabrik penggilingan padi yang bersikap tinggi 54 (45\%) responden dan 66 (55\%) responden yang memiliki sikap yang rendah. Hal itu dapat membuat para responden/pekerja malakukan tindakan dalam berperilaku di tempat kerjanya.

\section{Kesimpulan dan Saran \\ 1. Kesimpulan}

Berdasarkan hasil analisa dan pembahasan hubungan perilaku pekerja dengan penggunaan alat pelindung diri (APD) di pabrik penggilingan padi kabupaten sidrap adapun kesimpulannya yaitu :

1. pengetahuan pekerja di pabrik penggilingan padi tidak mempunyai hubungan terhadap pengunaan APD Berdasarkan hasil uji chi square di peroleh $p$ value $0,124(0,05)$

2. sikap pekerja/responden dipabrik penggilingan padi tidak mempunyai hubungan terhadap pengunaan APD Berdasarkan hasil uji chi square di peroleh $p$ value $0,544(0,05)$

3. tindakan pekerja/responden di pabrik penggilingan padi tidak mempunyai hubungan terhadap pengunaan APD 
Jurnal Sulolipu : Media Komunikasi Sivitas Akademika dan Masyarakat

Vol. 18 No 22018

e-issn : 2622-6960, p-issn : 0854-624X

Berdasarkan hasil uji chi square di

peroleh $p$ value $0,368(0,05)$

\section{Saran}

1. Diharapkan kepada pekerja di pabrik penggilingan padi agar dalam bekerja selalu menggunakan alat pelindung diri (APD).

2. Diharapkan pada pihak pabrik selalumemberikan bimmbingan atau penyuluhan terhadap pekerja dalam penggunaan alat pelindung diri (APD)

\section{DAFTAR PUSTAKA}

Andita Putri Tursina. 2013. Kinerja Usaha Penggilingan Padi, Studi Kasus Pada Tiga Usaha Penggilingan Padi Di Cianjur, Jawa Barat. (Online). http://eprints.uns.ac.id. Diakses pada tangal 13 Desember 2017

Ahmad Ali. 2006. Kinerja Industri Penggilingan Padi Di Indonesia. (online). http:// repository. unair.ac.id. Diakses pada tangal 13 Desember 2017

Ahmad Rahwan. 2012. Hubungan Pengetahuan Dan Sikap Karyawan Dengan Penggunaan Alat Pelindung Diri (Apd) Pada Pt Harta Samudra Pelabuhan Perikanan Nusantara Ambon Tahun 2012. (online). http://download.portalgaruda.org/article. . pada tangal 13 Desember 2017

Azwar Saifuddin. 2011. Sikap Manusia. Yogyakarta: Pustaka Pelajar

Budiyono Ismail Agus. 2015. Pengetahuan dan Sikap Pekerja dalam Penggunaan Alat Pelindung Diri pada Industri Informal Pengelasan di Desa Singajaya, Indramayu (online). https://media.neliti.com. Diakses pada tangal 13 Desember 2017

Buntarto. 2015. Panduan Praktis Keselamatan \& Kesehatan Kerja Untuk Industri . Yogyakarta : Pustakabarupress

Djojodibroto,D. 2000. Kesehatan Kerja Di Perusahaan. Jakarta: PT Gramedia Pustaka Utama

Eddy s.Gotto.2002. Pedoman Keselamatan Kerja. Bandung: Polman

Fitri Wijayati Dina. 2016. Hubungan Pengetahuan, Sikap Dan Tindakan Pengunaan Alat Pelinding Diri Terhadap Keluhan Gangguan Kulit Pada Petugas Sampah TPA Batu Layang Pontianak. (online). http://download.portalgaruda. Diakses pada tangal 13 Desember 2017

Kirun Wae. 2013. Jenis- Jenis Apat Pelindung Diri (APD). (Online). http://projectmedias.blogspot.com. Diakses 13 Desember 2017

Mandangi Adriani. 2013. Hubungan Antara Pengetahuan Dan Sikap Dengan Tindakan Pengunaan Alat Pelindung Diri Pada Pekerja Proyek Konstruksi Pembangunan Gedung Fakultas Kesehatan Masyarakat Universitas Manado. (online). http://journal.unair.ac.id Diakses pada tangal 13 Desember 2017

Notoatmodjo Soekidjo. 2010. IImu Perilaku Kesehatan. Jakarta: Rineka Cipta

Nugraha sigit. 2007. Analisis Model Pengolahan Padi (online). http://mekanisasi.litbang.pertanian.go.id. Diakses pada tangal 13 Desember 2017

Permatasari Gusti. 2016. Hubungan Pengetahuan Sikap Dan Kenyamanan Pekerja Dengan Pemakaian Alat Pelindung Diri (Apd) Di Bengkel Las Listrik Kecamatan Amuntai Tengah Kabupaten Hsu Tahun 2016. (online). http://download.portalgaruda.org/article. Diakses pada tangal 13 Desember 2017 
Jurnal Sulolipu : Media Komunikasi Sivitas Akademika dan Masyarakat

Vol. 18 No 22018

e-issn : 2622-6960, p-issn : 0854-624X

Rahayu Wulandari Dian, 2010. Pemakaian Alat Pelindung Diri Eco Kota Semarang. (online). http://lib.unnes.ac.id. Diakses pada tangal 13 Desember 2017

Rinawati Seviana, 2016. Pengaruh Tingkat Pengetahuan Terhadap Pelaksanaan Pemakaian Alat Pelindung Diri Sebagai Upaya Pencapaian Zero Accident Di Pt. X. (online). http://repository.usu.ac.id. Diakses pada tangal 13 Desember 2017

Santoso, Gempur. 2004. Buku Manajemen Kesehatan \& Keselamatan Kerja. Surabaya: Prestasi Pustaka

Sari Purnama Ika. 2010. Hubungan Pengetahuan Dan Sikap Penyapu Jalanan Dalam Pemakaian Alat Pelindung Diri (APD). (online). https://repository.unri.ac.id. Diakses pada tangal 13 Desember 2017

Suma'mur. 1988. Higene Perusahaan Dan Keselamatan Kerja. Jakarta: CV Haji Masagung

Sunaryo Kusmawan Wowo. 2014. Ergonomi dan K3 Kesehatan Keselamatan Kerja. Bandung: PT. Pemaja Rosdakarya Bandung

Susanto. 2005. Hubungan Pengetahuan Sikap Pemakaian Alat Pelindung Diri Dengan Praktik Penggunaan Alat Pelindung Diri Masker Pada Pekerja Penggilingan Padi (Huler) Di Kecamatan Kendal. Kabupaten Ngawi. Tahun 2005.(online). http://eprints.undip.ac.Id._Diakses pada tangal 13 Desember 2017

Triwibowo Cecep. 2013. Kesehatan lingkungan Dan K3. Yogyakarta: Nuha Medika

Zulkifli. 2013. Hubungan Pengetahuan, Sikap, Dan Tindakan Tenaga Kerja Dengan Pemakaian Alat Pelindung Diri (APD) Di PT. Sermani Steel Corporation Makassar.. Program Diploma III Jurusan Kesehatan Lingkungan. Politeknik Kesehatan Makassar: KTI Tidak Diterbitkan 